\title{
TIME SERIES FORECASTING FOR AVERAGE TEMPERATURE IN 96041 STATION USING LONG SHORT-TERM MEMORY MODEL
}

\author{
${ }^{1}$ Nancy Lusiana Damanik, ${ }^{1}$ Elida Pane, ${ }^{1}$ Kartika Dewi, ${ }^{1}$ Efrianses F.H Sinaga, \\ ${ }^{2}$ Jamaluddin, ${ }^{1}$ Hiras Sinaga, ${ }^{1}$ Marzuki Sinambela ${ }^{\boxplus}$ \\ ${ }^{1}$ Indonesia Meteorology, Climatology and Geophysics Agency, Regional I, Indonesia \\ ${ }^{2}$ Universitas Methodist Indonesia, Medan, Indonesia \\ Email: sinambela.m@gmail.com
}

DOI: https://doi.org/10.46880/jmika.Vol5No1.pp33-36

\begin{abstract}
An understanding of patterns and gauge of normal temperature joined of parameter climate and climate information for way better water asset administration and arranging during a bowl is exceptionally vital. Investigate climate patterns utilizing typical and neighborhood annually normal temperatures, compare and make perceptions. during this consider, we'll analyze nearby and ordinary normal temperature information in 96041 Station supported perception station in place. the foremost objective of this considers to seem the execution of the traditional temperature in an exceedingly single station and to foresee the conventional temperature information utilizing the Long memory Demonstrate approach. supported the results of ordinary informatics of investigating temperature with nearby temperature relationship, we got the show of preparing bend, remaining plot, and therefore the diffuse plot is appeared utilizing these codes. the nice execution of 96041 Station had an Mean Squared Error esteem of 0.01 and $R$ squared esteem 0.98, concerning zero will speak to superior quality of the indicator.
\end{abstract}

Keyword: Average Temperature, Forecasting, LSTM, Time-Series, 96041 Station.

\section{INTRODUCTION}

The 96041 station is one of the stations within the Medan zone which conveyed to watch the climate information. As a climate station, the 96041 stations deliver climate parameter information to educate the climate in-flight route zone, environment, climate issue, and horticulture (Bahram Choubin, Gholamreza Zehtabian, Ali Azareh, Elham Rafiei-Sardooi, n.d.; Choubin et al., 2018). One of the vital climate information in climate issues is the temperature normal. The temperature is an imperative calculate in all stages of the climate issue, and the foremost imperative climate figure influencing fire behavior. Higher temperatures cruel that heatwaves are likely to happen more frequently and final longer. Hotter temperatures can moreover lead to a chain response of other varieties around the world (NASA, 2010; Wikepedia, 2021). That's since expanding discussion temperature too influences the seas, climate designs, snow and ice, and plants and creatures. In this think about, we centered to assess the time-series of normal temperature collected from 96041 stations in Meteorology, Climatology and Geophysics Territorial 1, North Sumatera, Indonesia.

The most objective of this consider to analyze middle factors, assess and anticipate the time-series of normal temperature from 2008 until 2020 by utilizing the Long Short-Term Memory (LSTM) Demonstrate. The models were tried utilizing climate time arrangement information at each station which collected and compares the Root Cruel Square Mistake (RMSE) come about from the LTSM show. The comes about of this test appear that the LSTM demonstrate with/or without middle of the road variable has way better execution in case the time arrangement were accessible.

\section{LITERATURE REVIEW}

Long Short-Term Memory (LSTM) networks are a substantial branch of Recurrent Neural Networks $(\mathrm{RNN})$, capable of learning long-term territories (Laredo, Chen, Schütze, \& Sun, 2019; Wu, Yuan, Dong, Lin, \& Liu, 2018). LSTM is a model approach to solved some forecast issues. As a type of recurrent neural network, LSTM can learn the order dependence between items in a sequence. It also had the potential of being able to learn the context required to make predictions in time series forecasting problems, rather than having this context pre-specified and fixed (Ermatita et al., 2019; Fallah, Ganjkhani, Shamshirband, \& Chau, 2019). 


\section{DATA AND METHODS}

For this study, we utilized temperature data from the climate catalog of the Meteorology, Climatology, and Geophysics Regional I. The recorded temperature data was observed from 2008 to 2020, with the category of the average temperature on the Medan City as observed of 96041 stations. The selection of temperature series data provides a solid basis for evaluating the performance of observed that have been installed and reviewed in previous reports. The 96041station located with latitude and longitude coordinates are 3.54, 98.64. In this case, we focused on analyst the temperature data as time series recorded from each station in the Medan area and using LSTM to train, test, and predict the time series as a previous study (Afshin, Fahmi, Alizadeh, Sedghi, \& Kaveh, 2011; Hutapea, Pratiwi, Sarkis, Jaya, \& Sinambela, 2020; Salman, Heryadi, Abdurahman, \& Suparta, 2018).

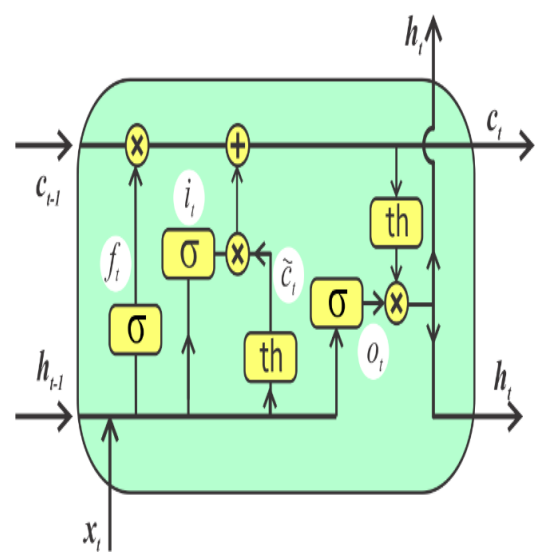

Legend:

\section{$x_{i}$ input}

$f_{1}$ forget gate

$i$ input gate

$\tilde{c}_{t}$ cell update

$c_{t}$ cell state

0, output gate

$h_{1}$ output

Figure 1. The LSTM Model (Stanford, 2015)

In figure 1, as a brief depiction, the input of the LSTM cell could be a time arrangement set of information $\mathrm{x}$ that experiences a few sigmoid actuation doors $\sigma$. Each entryway calculates a certain work to calculate the cell states. What we are given is as it were an awfully brief clarification of how LSTM works. For more data with respect to LSTM, it is still partway better to require a lesson on profound learning to advance get it the concepts.

The LSTM cell comprises of an input door which controls the stream of the input enactments into the memory cell, yield door which controls the yield stream of the cell actuation, and overlooks door, which channels the data from the input and past yield and chooses which one ought to be recollected or overlooked and dropped out. Other than three doors the LSTM cell contains cell upgrade which is more often than not tanh layer to be portion of the cell state. In each
LSTM cell, the three factors are coming into the cell, the current input $\mathrm{xt}_{\mathrm{t}}$, past yield $\mathrm{h}_{\mathrm{t}}-1$, and past cell state $\mathrm{c}_{\mathrm{t}}-1$. On the other hand, from each LSTM cell, two factors are getting out the current yield ht and the current cell state $\mathrm{ct}_{\mathrm{t}}$.

In this section, you will learn about the concepts of mean squared error and R-squared. Mean squared error (MSE) is the average sum of the squared difference between the actual value and the predicted or estimated value. It is also termed as mean squared deviation (MSD) (Kumar, 2020).

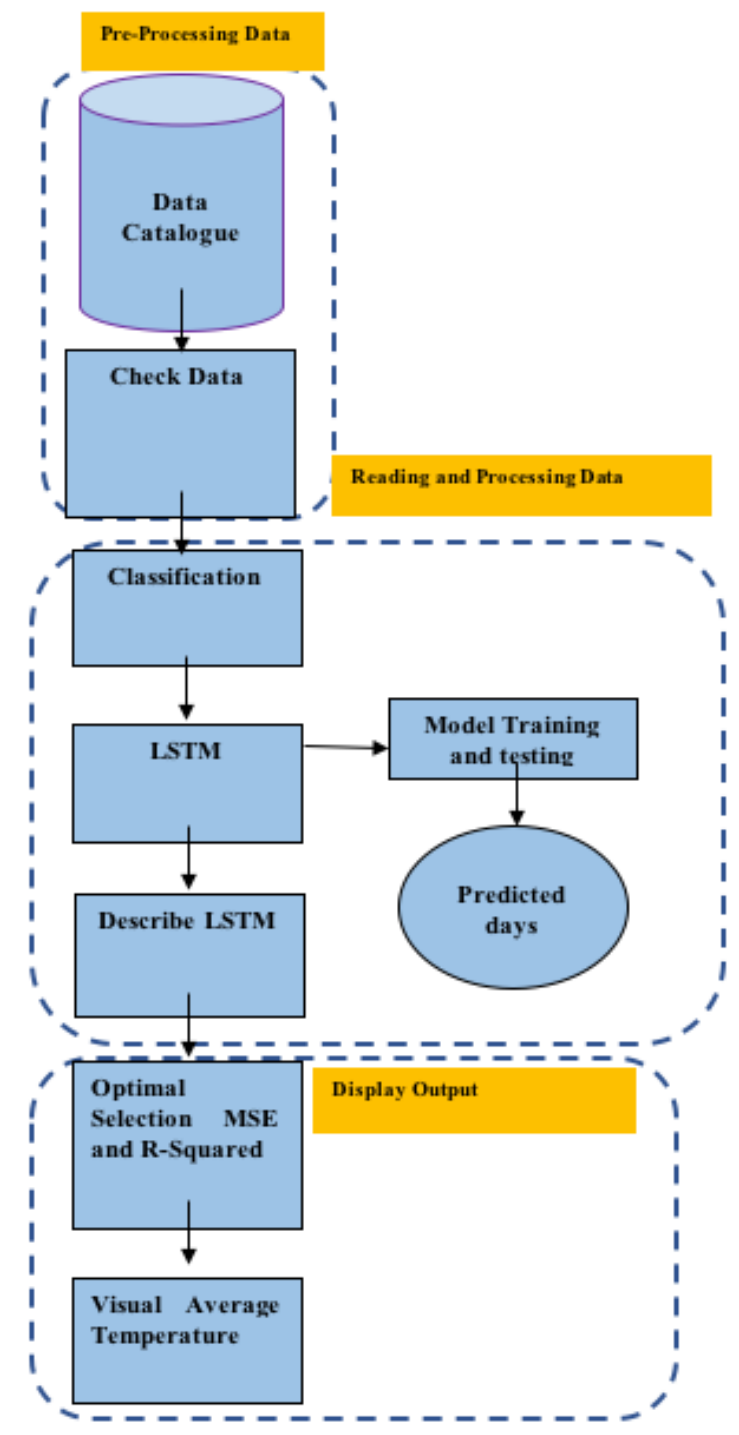

Figure 2. The flowchart of Forecasting Average Temperature

The flowchart in figure 2 appearing request determining technique based on LSTM, beginning from checked information from the information catalog until the visual normal temperature. 


\section{RESULT AND DISCUSSION}

The initial information of normal temperature had been computed to see that we demonstrate forecast was effective. In any case, it can be watched from the anticipated (n days) that the blunders are ordinarily from the unexpected rise or decrease within the data such as in days 350-360. But, based on the primary 75 days, the model can appropriately take after the design of the information. The visual of all information of succinct Balai Besar (96041) can be appeared in fig.3.
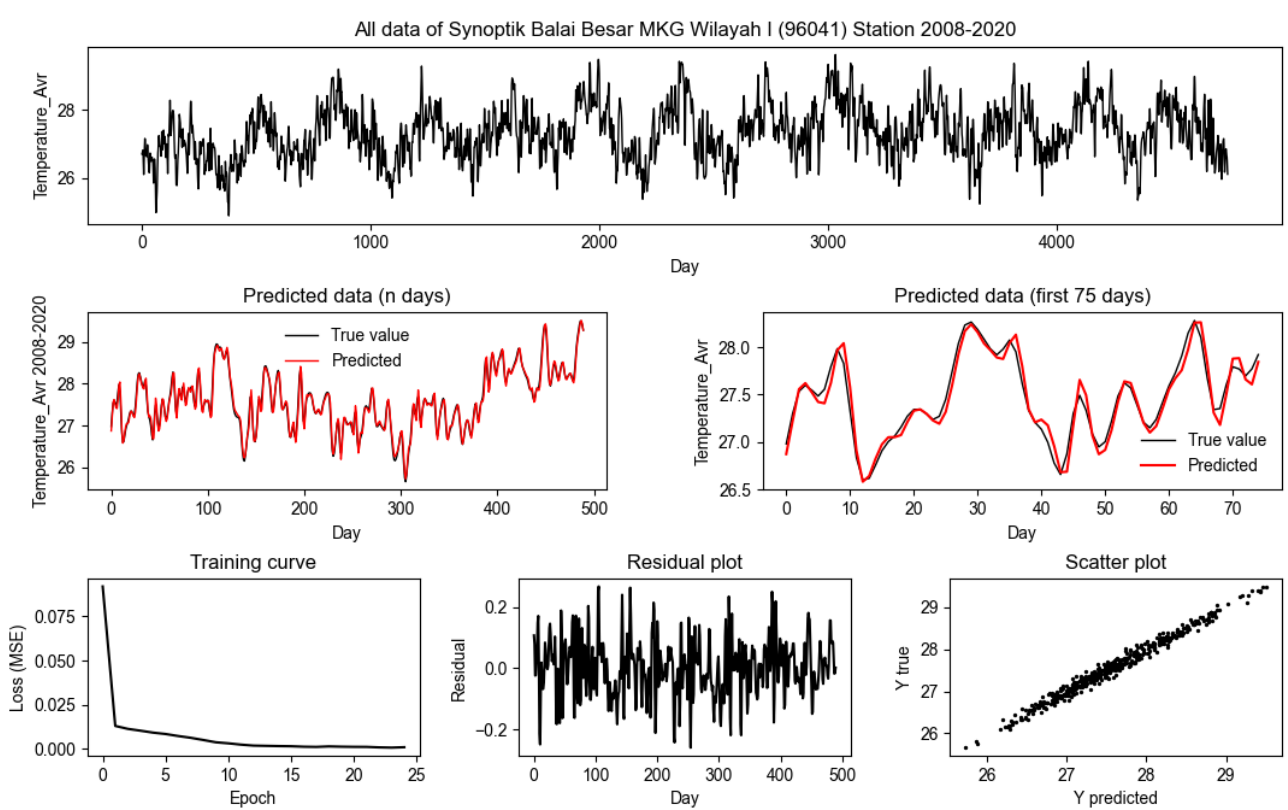

Figure 3. Stacked LSTM prediction results in 96041 Station

The preparing bend, remaining plot, and diffuse plot are appeared utilizing these codes. The representation of 96041 stations appears the esteem near to zero will speak to way better quality of the indicator within the relapse demonstrate. It can be seen from figure 3 that the Stacked LSTM performed best compared to the types of the station. We will also see that the single-cell worked incredibly utilizing 100 input days but we found that this kind of setup was as well computationally costly. The bidirectional LSTM moreover performed more awful with more input days. Based on the series data of temperature of 96041 stations, the MSE value is 0.01 , and R2 value is 0.98 .

\section{CONCLUSIONS}

In this study, we found that LSTM may be a great device for foreseeing normal temperature information. Based on the representation of 96041 stations that appeared, had a esteem near to zero will speak to superior quality of the estimator/predictor (relapse show). Be that as it may, ready to see from here that there are a few things to require domestic as lessons in utilizing LSTM. To begin with, more input days does not cruel that the demonstrate will be more precise.
Other than that, temperature information conditioning may, offer-assistance in making the demonstrate more accurate. Finally, indeed in spite of the fact that we haven't appeared, LSTM needs a certain sum of information to be connected. From there, able to envision that LSTM can be utilized for anticipating climate and patterns of normal temperature.

\section{REFERENCES}

Afshin, S., Fahmi, H., Alizadeh, A., Sedghi, H., \& Kaveh, F. (2011). Long term rainfall forecasting by integrated artificial neural network-fuzzy logic-wavelet model in karoon basin. Scientific Research and Essays, 6(6), 1200-1208. https://doi.org/10.5897/SRE10.448

Bahram Choubin, Gholamreza Zehtabian, Ali Azareh, Elham Rafiei-Sardooi, F. S.-H. \& Ö. K. (n.d.). Precipitation forecasting using classification and regression trees (CART) model: a comparative study of different approaches | SpringerLink.

Choubin, B., Zehtabian, G., Azareh, A., RafieiSardooi, E., Sajedi-Hosseini, F., \& Kişi, Ö. (2018). Precipitation forecasting using classification and regression trees (CART) model: a comparative study of different 
approaches. Environmental Earth Sciences, 77(8), 1-13. https://doi.org/10.1007/s12665018-7498-z

Ermatita, Pahendra, I., Darnila, E., Sadli, M., Sinambela, M., \& Fuadi, W. (2019). Peak Load Forecasting Based on Long Short Term Memory. Proceedings - 1st International Conference on Informatics, Multimedia, Cyber and Information System, ICIMCIS 2019, 137140 .

https://doi.org/10.1109/ICIMCIS48181.2019.89 85197

Fallah, S. N., Ganjkhani, M., Shamshirband, S., \& Chau, K. wing. (2019, January). Computational intelligence on short-term load forecasting: A methodological overview. Energies, Vol. 12. https://doi.org/10.3390/en12030393

Hutapea, M. I., Pratiwi, Y. Y., Sarkis, I. M., Jaya, I. K., \& Sinambela, M. (2020). Prediction of relative humidity based on long short-term memory network. AIP Conference Proceedings, 2221(March). https://doi.org/10.1063/5.0003171

Kumar, A. (2020). Mean Squared Error or R-Squared, Data Analytics.

Laredo, D., Chen, Z., Schütze, O., \& Sun, J. Q. (2019). A neural network-evolutionary computational framework for remaining useful life estimation of mechanical systems. Neural Networks, 116, 178-187.

https://doi.org/10.1016/j.neunet.2019.04.016

NASA. (2010). Global Warming.

Salman, A. G., Heryadi, Y., Abdurahman, E., \& Suparta, W. (2018). Weather forecasting using merged Long Short-Term Memory Model (LSTM) and Autoregressive Integrated Moving Average (ARIMA) Model. Journal of Computer Science, 14(7), 930-938.

https://doi.org/10.3844/jcssp.2018.930.938

Stanford. (2015). Understanding LSTM Networks. Https://Web.Stanford.Edu/Class/Cs379c/Archive /2018/Class_messages_listing/Content/Artificial _Neural_Network_Technology_Tutorials/OlahL STM-NEURAL-NETWORK-TUTORIAL-15.Pdf, $1-13$.

Wikepedia. (2021). Effects of climate change Wikipedia.

Wu, Y., Yuan, M., Dong, S., Lin, L., \& Liu, Y. (2018). Remaining useful life estimation of engineered systems using vanilla LSTM neural networks. Neurocomputing, 275, 167-179. https://doi.org/10.1016/j.neucom.2017.05.063 